\title{
THE LEVEL OF PSYCHOLOGICAL CAPITAL IN CHINESE UNIVERSITY EFL LECTURERS
}

\author{
Wu Yong1 \\ Department of Language and Literacy Education Faculty of Education, University of Malaya, Malaysia. \\ (Email: 704991373@qq.com) \\ Fonny Dameaty Hutagalung ${ }^{2}$ \\ Faculty of Education, University of Malaya, Malaysia. \\ Mohd Rashid Saad ${ }^{3}$ \\ Faculty of Education, University of Malaya, Malaysia.
}

Received date: $17-11-2019$

Revised date: 05-12-2019

Accepted date: 06-12-2019

Published date: 15-12-2019

To cite this document: Wu, Y., Hutagalung, F. D., \& Saad, M. R. (2019). The Level of Psychological Capital in Chinese University EFL Lecturers. International Journal of Education, Psychology and Counseling, 4 (33), 223-237.

DOI: $10.35631 /$ IJEPC.4330018

\begin{abstract}
The purpose of this research mainly investigates the level of psychological capital in Chinese university EFL lecturers. And the related level of aspects of psychological capital optimism, hope, self-efficacy, and resilience. 556 Chinese university EFL teachers in Zhejiang province have involved in this study and there is a high level of psychological capital. The mean value for the four dimensions, hope, and resilience, belong to the moderator level, while; efficacy and optimism are high levels. And then some discussions are proposed.
\end{abstract}

Keywords: Psychological Capital, Chinese University, EFL, Lecturers, Level

\section{Introduction}

Recently, teaching is considered as a high-stress profession because many teachers is experiencing serious emotional problems associated with work stress (Montgomery \& Rupp, 2005). Meanwhile, stress could interfere with individual's well-being and lead to the weaken performance (Folkman et al., 1986). When teachers felt stressed and ill-being, teachers will have a negative impact on students academic and behavioral outcomes (Wentzel, 2010). In recent years, research which directly discusses the teachers' psychological capital is increasing (Collie et al., 2012). Because it has been reported that EFL teacher experienced frustration and become less engaged in their teaching work, eventually leading to ill-being and mental problems (Sutton\& Wheatley, 2003). Symptoms may also be present about teachers, such as low morale, cynicism, over emotionalism, suspiciousness, depression, rigidity, absenteeism, retirement and burnout (Emmer, 1994). Once teachers experienced burnout, they will have less tolerant of students' behavior problems and tend to have more negative relationships with their 
students (Ross et al., 1989) and may treat their students overly strictly and demonstrate low levels of engagement and commitment toward their jobs (Friedman, 2004).

Even if research on language teachers' positive psychology is generally rare, recently there have been more and more voices calling for integrating positive psychology into second language acquisition (MacIntyre, Gregersen, \& Mercer, 2016). Mercer (2016) even called for more teacher-centeredness in the field of language learning psychology, arguing that positive psychology plays a central role not just for the teacher themselves but also for their students and the whole of society.

\section{Literature Review}

Under the movement of positive psychology, Luthans realized negative psychology problems and started to expand the positive psychology to the organizational environment under the name positive organizational behaviour. Although the idea of psychological capital originated from the movement of positive psychology and positive organizational behavior theory, Luthans (2007) stressed and strongly agreed that positive experience could build various psychological resources and lead to many outcomes. Subsequently, Luthans and his colleagues combined hope, efficacy, resilience, and optimism these four psychological resources named as psychological capital.

The construct of hope was derived from Snyder's (2002) hope theory. It is defined as a positive motivational state that is based on an interactively derived sense of successful agency (goaldirected energy), and pathways (planning to meet goals). Individuals with high hopes are those who will make good use of their pathway thinking (way power) so as to find different ways of achieving their goals, and to make good use of their agency thinking (willpower) so as to assist their search for the ends in achieving their goals. Some researchers have found that people with high hopes performed better than their low-hope counterparts in the areas of athletics (Curry et al., 1997), psychological adjustments and psychotherapy (Kwon, 2002), and other performances (Reichard, Avey, Lopez, \& Dollwet, 2013). As a result, more and more scholars are also beginning to apply the hope theory within the education domain (Gallegher, Marques, \& Lopez, 2017). Results from these studies seemed to suggest that teachers with high levels of hope tend to view students' misbehaviors as opportunities for them to try different classroom management techniques. Snyder et al. (1991) had firstly indicated that the level of teachers' hope is connected to some constructs with classroom management. This occurred when they examined a sample of 278 teachers in Alabama, Georgia, and California. They noted that teachers with high hopes were better able to cope with their goal blockages than teachers with low hopes.

Most research that had investigated self-efficacy had stemmed from other studies which focused on social cognition (Bandura, 1997). The term, efficacy, has been defined as "the individual's conviction or confidence about his/her abilities to mobilise motivation, cognitive resources or courses of action that are needed to execute a specific task within a given context successfully" (Stajkovic \& Luthans, 1998b, p. 66). This has been reiterated by Bandura (1999) whose works also mentioned that it is about the individual's ability to believe in his/her competence to perform. Bandura (1999) indicated that when the individual's self-efficacy is high, he/she also possesses high levels of confidence; he/she then has the ability to deal with the problem at large. When the problem is resolved, he/she has a level of self-satisfaction that enables the individual to further exhibit better work behaviors. In other words, this means that teachers with high levels of self-efficacy were more likely to motivate and encourage their 
students even if there were challenges ahead. Such individuals were also more likely to introduce new teaching methods, and form more positive relationships with their students (Mojave \& Tami, 2012).

Resilience is the individual's ability to recover from adversities, and to emerge as stronger individuals. This ability has an empowering effect on the individuals (Luthans, et al., 2007) because they have the capacity to move towards their own psychological, social, cultural, and physical resources that would be used to serve their own well-being (Luthans \& Youssef, 2004). Teachers' resiliency is their ability to adjust to varied situations, and to increase their competence in the face of adverse conditions (Gordon \&Coscarelli, 1996). Some researchers (Kitching, Morgan \& O'Leary, 2009) have focused on what factors helped to sustain teachers so as to enable them to thrive rather than just survive in the profession. Witt (1991) noted that teachers with high resilience were more likely to commit to their organizations; they were also more likely to help their colleagues with problems, promote a favourable work climate, tolerate inconveniences without complaints, and they managed their classrooms better with better job satisfaction. Salgado (2005) also pointed out that a teacher with high resilience is more likely to be socially competent, thereby satisfying the need for affection, respect, and optimal social life. This in turn, enables them to manage power better, achieve goals, make better decisions as well as procure a happy, productive, and healthy life easily.

The concept of optimism was developed by Scheier and Carver (1985) based on the outcome expectancies. Optimism is considered as a positive attitude towards life (Seligman, 2002), and also believed that optimism or pessimism in a man would be dependent on how problems were explained. Optimistic people made a lasting and universal attribution to positive events, and a brief and concrete attribution to adverse events. Several studies (Duckworth, Quinn, \& Seligman 2009) have examined the role that optimism plays in the teaching profession and teaching performance. It was revealed that optimistic teachers showed higher levels of teaching effectiveness by taking more risks; they also carried a positive attitude towards their students (even problematic students), and they perceived obstacles as challenges that can be conquered (Duckworth, Quinn, \& Seligman, 2009).

Psychological capital has been conducted and indicated positively correlated with organizational commitment, job satisfaction, organizational citizenship behavior (Yildiz, 2016). Moreover, the aim of psychological capital is to reveal the strengths and superiorities of the individuals and for healthy people to be made stronger and more productive (Seligman, 1998). In addition, psychological capital can help individuals to adapt to their environment and cope with stress and create the individual's advantageous strengths to overcome difficulties and pursue a productive life. Hence, psychological capital can be established as a predictor of work performance, as well as of the attitudes and behaviors of employees towards their work (Avey et al., 2011).

Although more and more scholars are applying psychological capital into the education field, psychological capital integrated into education is still a new and emerging topic. Moreover, the majority of researches are mainly focused on workers, nurse, managers, and soldiers. Thus, there are many kinds of research on strengthening leaders and followers to make the entire organization more successful. Little researches on the subject of the teachers' psychological capital are made. And the limited research on researches still focuses on elementary teachers, high teachers, special education teachers (Lee, et al., 2017), and EFL teachers in high education context are always be ignored. 
Furthermore, current researches about psychological capital are mainly in western countries, and eastern countries are still ignored (Chen et al., 2017). Due to the culture difference between western countries and eastern countries under cross-context, the result of psychology capital will be different. Thus, there is scant research about the Chinese university EFL lecturers' real level of psychosocial capital.

This study aims to analyze the level of positive psychological capital in Chinese university lecturers. By this research, it can present a new view to exploring the complex construct of psychological capital and explore the theory of positive psychology so that add to the general body of knowledge, research, literature review and data of this area is of significant value. It also could help administrators of universities raise awareness regarding the importance of teachers' positive psychological capital in foreign language classroom management, so that improve the quality of foreign language teaching. The results of this study also could provide valuable information for administrators and higher education department in Zhejiang province to promote the development of psychological capital in university EFL teachers so that to improve EFL teachers' professional development.

\section{Method}

\section{Paticipants and Procedure}

This study is a cross-section survey research design (Creswell, 2012). The researcher used cross-sectional survey because it could be used in quantitative research and it could provide the opportunity to administer a sample or to an entire population of people to describe target population's attitudes, opinions, behaviors, even characteristics (Creswell, 2014).

Since probability sampling is frequently used in non-experimental survey research (Johnson \& Christensen, 2008), the selection of samples for this research was conducted in the multi-stage sampling method. The population of this research consists of Chinese university EFL lecturers in Zhejiang province. The participants comprise 556 Chinese university EFL lecturers in Zhejiang Province, China. Female respondents were 357 (64.21\%), and male respondents were 199 (35.79 \%). EFL lecturers are encouraged to involve in this study and completed filledsurveys were used as data for this study.

\section{Instrument}

In this study, psychological capital questionnaire with 24 items was adopted to measure the Chinese university EFL teachers' psychological capital. The questionnaire of psychological capital is designed to assess the four components of Psychological Capital: hope, self-efficacy, optimism, and resilience. Six items evaluate each component. The PCQ-24 items instrument is a 6-point Likert-type scale (1=strongly disagree, $2=$ disagree, $3=$ somewhat disagree, $4=$ somewhat agree, $5=$ agree, $6=$ strongly agree). In order to maintain a consistently positive direction of responses, item 13, Item 20 and item 23, these three items need to reverse coded. An example of item for assessing the hope facet is "I can think of many ways to reach my current teaching goals." efficacy item is "I feel confident contributing to discussions during class instruction. Resilience is measured with items such as "I can get through difficult times in teaching because I have experienced difficulty before." Moreover, a sample of optimism item is "I always look on the bright side of things regarding my teaching process." 
According to Luthans, Avolio, Avey, and Norman (2007), the research results assess the overall psychological capital construct yielded Cronbach alphas $=0.88,0.89,0.89$, and 0.89. Each subscale was also evaluated: hope $(0.72,0.75,0.80,0.76)$, self-efficacy $(0.75,0.84,0.85,0.75)$, optimism $(0.74,0.69,0.76,0.79)$, and resilience $(0.71,0.71,0.66,0.72)$. Therefore, PCQ-24 has high reliability and validity so that can be used into this research.

\section{Reliability of Instrument}

According to Table 1, the analysis of the pilot study data $(\mathrm{N}=253)$, the results show that the reliability value of psychological capital scale exceeds the desired standard 0.70 (Psychological Capital $\alpha=0.832$ ), (PERMA $\alpha=0.882$ ). Moreover, the psychological capital' sub-construct reliability ranges from 0.720 to 0.813 .

Table 1: The Cronbach's Alpha Coefficient of the Pilot Study (N=253)

\begin{tabular}{|c|c|c|c|}
\hline Construct & $\begin{array}{c}\text { Sub- } \\
\text { Construct }\end{array}$ & $\begin{array}{c}\text { Whole } \\
\text { Cronbach } \\
\text { Alpha }\end{array}$ & $\begin{array}{l}\text { Sub-Construct's } \\
\text { Cronbach's Alpha }\end{array}$ \\
\hline \multirow{4}{*}{$\begin{array}{c}\text { Psychological } \\
\text { Capital }\end{array}$} & Hope & \multirow{4}{*}{0.832} & 0.720 \\
\hline & Efficacy & & 0.801 \\
\hline & Resilience & & 0.808 \\
\hline & Optimism & & 0.813 \\
\hline
\end{tabular}

\section{Data Analysis}

According to Cohen et al. (2011), descriptive statistics include frequencies, measures of central tendency (means, modes, and medians), measures of dispersal (range, interquartile range, and standard deviations), cross-tabulations and standardized scores. Therefore, this research question can be used the mean and standard deviation to describe the statistics.

In this study, the summated scale is reported in term of the mean and standard deviation of each of the dimensions of Chinese university teachers' psychological capital. Since the summated scale is a standard procedure for measuring abstract constructions and it consists of multiple items which are designed to measure the same construct according to Hair et al., (2010). Moreover, the composite mean obtained from the summated scale was used to assess the level of Chinese university EFL teachers' psychological capital. The interpretations for level according to mean which are divided into low, medium and high with an equal interval are presented in Table 1.

Table 2: Interpretation of Level According to Mean of 6 points

\begin{tabular}{cc}
\hline Mean & Interpretations (level) \\
\hline $1-2.49$ & Low \\
$2.5-4.49$ & Medium \\
$4.5-6.0$ & High \\
\hline
\end{tabular}

Source: Pimdee \& Paksanondha, 2013, p.83

\section{Results}

Once the data were cleaned and ensured for quality, descriptive statistics were performed by using SPSS to identify the general characteristics of the 556 respondents. Some variables had been used to describe the sample characteristics by the valid 556 respondents to the survey 
questionnaires. The means would be interpreted as the level of EFL teachers' psychological capital displayed in Table 2 and Figure 1. The results of the analysis are shown in Table 2.

Table 3: Descriptive Analysis for EFL Teachers' Psychological Capital (N=556)

\begin{tabular}{lcccc}
\hline Dimension & N & Mean & $\begin{array}{c}\text { Standard } \\
\text { Deviation }\end{array}$ & Level \\
\hline Hope & 556 & 4.45 & 0.78 & Moderate \\
\hline Efficacy & 556 & 4.55 & 0.83 & High \\
\hline Resilience & 556 & 4.43 & 0.83 & Moderate \\
\hline Optimism & 556 & 4.60 & 0.83 & High \\
\hline Overall Mean & 556 & 4.50 & 0.61 & High
\end{tabular}

Note. Mean-low level=1.00-2.49; Moderate level= 2.5 -4.49; High level=4.5-6

From Table 3, the overall mean value of teachers' psychological capital is moderate $(M=4.50$, $\mathrm{SD}=0.61$ ) which imply that there is a high level of psychological capital among Chinese university EFL teachers in Zhejiang province. The mean value for the four dimensions, hope and resilience, belong to the moderator level, while; efficacy and optimism are high levels. Among the four dimensions, optimism dimension which reflects the highest mean of EFL teachers attach to EFL psychological capital $(\mathrm{M}=4.59, \mathrm{SD}=0.83)$, followed by efficacy dimension, which reflects the EFL teachers' efficacy on the EFL teachers' psychological capital $(\mathrm{M}=4.55, \mathrm{SD}=.83)$. Moreover, then, the hope dimension followed by mean=4.45, $\mathrm{SD}=0.78$. Finally, it is resilience $(\mathrm{M}=4.43, \mathrm{SD}=0.83)$ which is at a moderate level.

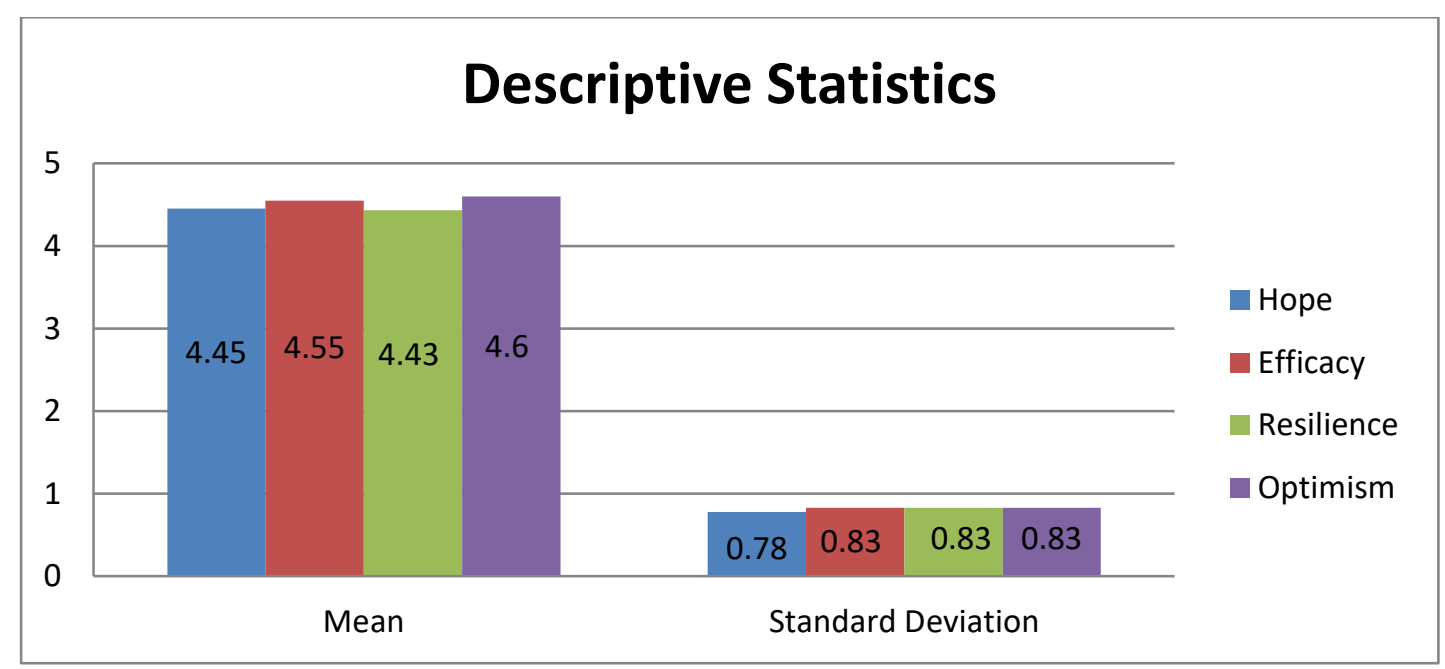

Figure 1. Mean and Standard Deviation of EFL Teachers' Psychological Capital

Additionally, the researcher displayed the mean and standard deviation for each of the items according to each of EFL teachers' psychological capital dimensions in the following Tables. The explanation in this study is based on which particular item demonstrated higher or lower mean than each dimension means of Chinese university EFL teachers' psychological capital. 


\section{Dimension 1: Hope}

Table 4 displays the means and standard deviations of Hope dimension with six items.

Table 4: Mean and Standard Deviation for Each of the Items in Hope dimension

\begin{tabular}{|c|c|c|c|c|}
\hline Item & Description & Mea & S. D & evel \\
\hline 1 & $\begin{array}{l}\text { If I should find myself in a jam, I could think of } \\
\text { many ways to get out of it. }\end{array}$ & 4.50 & 0.91 & high \\
\hline 2 & $\begin{array}{l}\text { At present, I am energetically pursuing my } \\
\text { teaching goals. }\end{array}$ & 4.50 & 0.93 & high \\
\hline 3 & There are lots of ways around any problem. & 4.55 & 0.94 & high \\
\hline 4 & $\begin{array}{l}\text { Right now I see myself as being pretty successful } \\
\text { in teaching. }\end{array}$ & 4.23 & 0.89 & Moderator \\
\hline 5 & $\begin{array}{l}\text { I can think of many ways to reach my current } \\
\text { teaching goals. }\end{array}$ & 4.45 & 0.86 & Moderate \\
\hline 6 & $\begin{array}{l}\text { At this time, I am meeting the goals that I have set } \\
\text { for myself. }\end{array}$ & 4.46 & 0.91 & Moderate \\
\hline \multicolumn{2}{|c|}{ Overall Mean } & 4.45 & 0.78 & Moderate \\
\hline
\end{tabular}

Note. Mean-low level=1.00-2.49; Moderate level= 2.5 -4.49; High level=4.5-6

The results of the descriptive analysis for each of the items shown in Table 3, four items have a higher mean than the overall mean of hope dimension $(\mathrm{M}=4.45$, S.D. $=0.78)$. These three items are item $1(\mathrm{M}=4.50$, S.D. $=0.91)$, item $2(\mathrm{M}=4.50$, S.D. $=0.93)$, item 3 ( $M=4.55$, S.D. $=0.94)$. However, item 4 is lowest with Mean=4.23, S.D. $=0.89$. These indicated that Chinese university EFL teachers involved in this study felt they are some problems in teaching. However, most Chinese university EFL teachers still hold hope in their teaching. Moreover, the other three items are a moderate level of item 4, 5, 6, and the overall mean level of hope dimension is moderate level.

\section{Dimension 2: Efficacy}

The efficacy dimension comprised of six items. The mean and standard deviations for all of the six items are shown in Table 5.

As can be seen in Table 4, three items have a higher mean than the overall mean of efficacy dimension $(\mathrm{M}=4.53$, S.D. $=0.81)$. These three items are item $9(\mathrm{M}=4.58$, S.D. $=0.91), 10$ $(\mathrm{M}=4.56$, S.D. $=0.94), 12(\mathrm{M}=4.66$, S.D. $=0.88)$. Meanwhile, three items are of high level, and the other three items are mediator level. In these six items, item 7 is lowest with Mean $=4.43$, S.D. $=.98$. These indicated that the Chinese university EFL teachers involved in this study have no confidence in analysing a long-term problem. Furthermore, the mean of the level of the overall mean is high level. 
Table 5: Mean and Standard Deviation for Each of The Items in Efficacy Dimension

\begin{tabular}{|c|c|c|c|c|}
\hline Item & Description & Mean & S.D & Level \\
\hline 7 & $\begin{array}{l}\text { I feel confident analysing a long-term problem to } \\
\text { find a solution. }\end{array}$ & 4.43 & 0.98 & Moderate \\
\hline 8 & $\begin{array}{l}\text { I feel confident in representing my performance in } \\
\text { meetings with instructors/faculty. }\end{array}$ & 4.49 & 0.97 & Moderate \\
\hline 9 & $\begin{array}{l}\text { I feel confident contributing to discussions } \\
\text { during class instruction. }\end{array}$ & 4.58 & 0.91 & High \\
\hline 10 & $\begin{array}{l}\text { I feel confident helping to set targets/goals for } \\
\text { myself. }\end{array}$ & 4.56 & 0.94 & High \\
\hline 11 & $\begin{array}{l}\text { I feel confident contacting people outside the } \\
\text { class (e.g., other instructors, head of the } \\
\text { Language and Literacy Department) to } \\
\text { discuss problems. }\end{array}$ & 4.45 & 0.95 & Moderate \\
\hline 12 & $\begin{array}{l}\text { I feel confident presenting information to a group } \\
\text { of colleagues. }\end{array}$ & 4.66 & 0.88 & High \\
\hline \multicolumn{2}{|c|}{ Overall Mean } & 4.53 & 0.81 & High \\
\hline
\end{tabular}

Note. Mean-low level=1.00-2.49; Moderate level= 2.5 -4.49; High level=4.5-6

\section{Dimension 3: Resilience}

The resilience dimension has six items. The mean and standard deviations for all of the six items are shown in Table 6.

From Table 6, there are three items with a higher mean than the overall mean of resilience dimension ( $\mathrm{M}=4.44$, S.D. $=0.81)$. These three items are item $13(\mathrm{M}=4.53$, S.D. $=0.95)$, item 14 (M=4.49, S.D. =0.93), and item 15 (M=4.65, S.D. =0.92). Moreover, four items have a moderate level. However, B18 is lowest with Mean=4.26, S.D. $=0.10$, which is low level in resilience dimension. These indicated that the Chinese university EFL teachers involved in this study are difficult to handle many things at a time during work. What is more, the four items level in resilience dimension are a high level which are item 14, 16 and 17, 18, and the level of the overall mean also a moderate level.

Table 6: Mean and Standard Deviation for Each of the Items in Resilience Dimension $(\mathrm{N}=556)$

\begin{tabular}{llrrr}
\hline Ite & Description & Mean & S.D & Level \\
\hline 13 & $\begin{array}{c}\text { When I have a setback in work, I have trouble } \\
\text { recovering from it, moving on. }\end{array}$ & 4.53 & 0.95 & High \\
\hline $\begin{array}{c}\text { I usually manage difficulties one way or another } \\
\text { during teaching. }\end{array}$ & 4.49 & 0.93 & $\begin{array}{r}\text { Moderat } \\
\text { e }\end{array}$
\end{tabular}




\begin{tabular}{|c|c|c|c|c|}
\hline 15 & $\begin{array}{l}\text { If I have to, I can be "on my own," so to speak, } \\
\text { when work. }\end{array}$ & 4.65 & 0.92 & High \\
\hline 16 & I usually take stressful flight situations in stride. & 4.35 & 1.0 & Moderat \\
\hline 17 & $\begin{array}{l}\text { I can get through difficult times in teaching } \\
\text { because I have experienced difficulty } \\
\text { before. }\end{array}$ & 4.40 & 0.97 & $\begin{array}{r}\mathrm{e} \\
\text { Moderat } \\
\mathrm{e}\end{array}$ \\
\hline 18 & $\begin{array}{l}\text { I feel I can handle many things at a time during } \\
\text { work. }\end{array}$ & 4.26 & 1.0 & $\begin{array}{r}\text { Moderat } \\
\mathrm{e}\end{array}$ \\
\hline \multicolumn{2}{|c|}{ Overall Mean } & 4.44 & 0.81 & Moderat \\
\hline
\end{tabular}

Note. Mean-low level=0.00-2.49; Moderate level= 2.5 -4.49; High level=4.5-6

\section{Dimension 4: Optimism}

The optimism dimension comprised of six items. The mean and standard deviations for all of the six items are shown in Table 7.

According to Table 7, four items have a higher mean than the overall mean of optimism dimension $(\mathrm{M}=4.61$, S.D. $=0.87)$. These four items are item $21(\mathrm{M}=4.63$, S.D. $=0.95), 22$ $(M=4.65$, S.D. $=0.94), 23(M=4.62$, S.D. $=1.00)$, and $24(M=4.70$, S.D. $=0.93)$. However, the lowest item is item 19 with Mean=4.33, S.D. $=1.1$, which indicated that when things are uncertain for Chinese university EFL teachers in work, the majority of them felt depression instead of optimism. Furthermore, five items except for item 19 and the level of the overall mean are high level.

Table 7: Mean and Standard Deviation for Each of The Items in Optimism Dimension

\begin{tabular}{|c|c|c|c|c|}
\hline Item & Description & Mean & S. D & Level \\
\hline 19 & $\begin{array}{l}\text { When things are uncertain for me in work, I } \\
\text { usually expect the best. }\end{array}$ & 4.33 & 1.1 & moderate \\
\hline 20 & $\begin{array}{l}\text { If something can go wrong for me work-wise, } \\
\text { it will. }\end{array}$ & 4.59 & 0.95 & High \\
\hline 21 & $\begin{array}{l}\text { I always look on the bright side of things } \\
\text { regarding my teaching process. }\end{array}$ & 4.63 & 0.95 & High \\
\hline 22 & $\begin{array}{l}\text { I am optimistic about what will happen to me } \\
\text { in the future as it pertains to work. }\end{array}$ & 4.65 & 0.94 & High \\
\hline 23 & $\begin{array}{l}\text { As a teacher, things never work out the way I } \\
\text { want them to. }\end{array}$ & 4.62 & 1.00 & High \\
\hline 24 & $\begin{array}{l}\text { I approach work as if "every cloud has a } \\
\text { silver lining." }\end{array}$ & 4.70 & 0.93 & High \\
\hline Overa & Mean & 4.61 & 0.87 & High \\
\hline
\end{tabular}

Note. Mean-low level=1.00-2.49; Moderate level= 2.5 -4.49; High level=4.5-6 
In conclusion, the data of this study indicated that Chinese university EFL showed a high level of psychological capital in general which reflects Chinese university EFL teachers in Zhejiang province involved in the research has a high level of hope, efficacy, resilience, and optimism.

\section{Discussion}

Psychological capital as the study and application of positively oriented human resource strengths and psychological capacities that can be measured, developed, and effectively managed for performance improvement in the workplace (Luthans, et al., (2007). The descriptive analysis of data of 556 participants included in this research showed that Chinese university EFL teachers in Zhejiang province indicated the high level of psychological capital.

In Chinese high education context, this result is inconsistency with the previous findings by Kurt and Demirbolat (2019), who got the result, is that psychological capital of teachers in Turkey is moderate level and four dimensions of psychological capital are all medium levels. Additionally, Shen et al. (2014) revealed that Chinese university teacher to have a moderate level of psychological capital in the capital of Liaoning province in Northeast China. This research is also an inconsistency with the result of Lee (2018), which indicated 310 university teachers in Shanxi province in the Northwest part of China had a medium level of psychological capital. However, the finding of this research confirms those scholars such as Cheung (2008) and Lee (2017). They suggested that teachers with a high level of psychological capital will have a more positive and optimistic attitude towards their teaching. The higher teacher's efficacy, hope, resilience and optimism, the more devoted themselves are to work.

On the other hand, the Chinese university EFL teachers' scores for 4 dimensions of psychological capital were all close to 5 points, showing high level and the dimension from the highest level to the lowest level is optimism, efficacy, hope and resilience according to mean. This is inconsistent with Fu (2014) and Lee (2018). In Lee's research, the highest dimension to lowest dimension is efficacy, resilience, hope and optimism while, in Fu (2014)'s research, hope was highest, followed by efficacy, and optimism, the resilience is lowest. The biggest difference from these researches because of the different research districts and respondents, which is in the northwest part of China and the other, is in Taiwan province. The respondents of $\mathrm{Fu}$ (2014) and Lee (2018) are kindergarten teachers and primary school teachers. Meanwhile, the reason why optimism is the highest and resilience is lowest dimension in this research because most of the EFL teachers still have an optimistic attitude towards their language teaching $\mathrm{t}$ but it is difficult to "bounce back" from their frustration when they met because resilience research is still a new and strange filed to Chinese researchers. In hope dimension, the participants showed a medium level of agreement on the statements that most of the teachers are willing tenaciously to pursue the goal that deals with language teaching problems. This result was confirmed by Snyder et al. (2000) conclusion. Thus, this finding revealed teachers with hope have the ability to develop various teaching methods, problemsolving, solving a problem quickly and easily, and focusing on achieving the teaching goal.

Furthermore, the respondents showed a high level of agreement on the statement about efficacy. Most studies have agreed that when teachers are highly efficacy, they will have highquality classroom management, more likely to stay in teaching careers, spend more time teaching, contribute greater efforts in classroom planning and organization and demonstrate greater enthusiasm for teaching (Cheung \& Lau, 2008). This result is supported by some researchers stated that teachers with a high level of efficacy are always less critical to students' mistakes and have good willing to devote themselves to promote students' achievement and 
help student cope with some problems so that students are encouraged to involve more their efforts into their language learning (Ho \& Hau, 2004). Thus, EFL teachers can make a contribution to the language learners and teaching performance and have confidence in teaching, decisiveness in the thought and teaching. By increasing Chinese university EFL teachers" efficacy may help to increase the level of their language teaching. Besides that, Rizvi and Elliot (2005) believed that teacher efficacy is an important dimension of teacher professionalism. Indeed, high level of teachers' efficacy capacities is correlated with their positive teaching and performance (Luthans, Youssef, \& Avolio, 2007).

Looking at the resilience dimension, the respondents also showed the medium level of agreements that resilience is efficient domination of psychological capital which influences on College English classroom management. Brunetti (2006) found that the level of resilience is an especially essential factor which decided teachers could continue to have productive teaching when they faced more challenges in the school setting. Teachers with a high level of resilience could hele themselves to deal with stress, ill-being and reduce the emotional exhaustion even burnout (Chang, 2009). And it also supported by Luo (2019), who used 1400 college and university young lectures in Guangdong province and got the result which the resilience level is medium level. Thus, resilience can help teachers to thrive, flourish and sustain their effectiveness in the teaching profession (Gu \& Day, 2007). In other words, resilient teacher could conquer the negative emotions or stressful events by utilizing personal or environmental resources to bounce back from frustrations, failure so that bounce back to positive psychology (Bobek, 2002). EFL teachers with resilient can control negative emotions, focus on teaching and preventing the mistakes so that handle power better, achieve goals and make a better decision in their language teaching.

Eventually, in optimism dimension, the respondents have a high level on the statement, and it showed the highest dimension compared with the other three dimensions. Seligman describes it as individuals with a fairly positive general view of their futures (Isaacowitz \& Seligman, 2002). It meant that teachers with a higher level of optimism have a positive attitude toward life and job and optimistic teachers are better able to face threatening frustration with positive emotions so that have effective coping skills to deal with all challenges (Iwanaga et al. 2004). Hence, on the basis of optimism, teachers with high optimism could be more positive, increase teaching efficiency and motivation, and develop a good relationship with students.

Hence, this finding is in accordance with the viewpoints conducted by Seligman et al. (2011). However, this result is against the researches of Lee (1998) and Chang (2002), which stated that Asians or Asian American teachers were more pessimistic. Due to teachers' optimism would be affected by sociocultural conditions or cross-culture factors, this inconsistency existed.

In addition, teaching is an emotional practice (Hargeaves, 1998) which affects both teachers' and learners' experience of classroom learning. While, positivity can be tapped when are needed based on the approach of Fredrickson' broaden-and-build (2009), teachers as the main player in school, should increase the quality of their education so that teaching and learning will become more effective. Therefore, to increase EFL teaching efficient and high quality of College English teaching, the Ministry of Education and administers of universities in Zhejiang province should look into ways to strengthen the level of four dominations of psychological capital. 


\section{Conclusion}

This study indicated that Chinese university EFL teachers in Zhejiang province have a high level of psychological capital by the descriptive analysis. The results showed that the level of psychological capital among Chinese university EFL teachers in Zhejiang province is high. The hope and resilience dimensions of EFL teachers' psychological capital are at a moderate level, while, the efficacy and optimism are at a high level. However, the dimension of resilience showed the lowest level and optimism is the highest level in the psychological capital. This meant that policymakers, administrators, university EFL teachers should pay more attention to hope and resilience aspects.

\section{Reference}

Avey, J. B., Reichard, R. J., Luthans, F., \& Mhatre, K. H. (2011). A meta-analysis of the impact of positive psychological capital on employee attitudes, behaviours, and performance. Human Resource Development Quarterly, 22(2), 127-152.

Bandura, A. (1997). Self-efficacy: The exercise of control. New York: W.H. Freeman.

Bandura, A. (1999). A social cognitive theory of personality. In L. Pervin, \& O. John (Ed.), Handbook of personality (2nd ed.) (pp.154-196). New York: Guilford Publications.

Bobek, B. L. (2002). Teacher Resiliency. The Clearing House, 75, 202-205.

Brunetti, G. J. (2006). Resilience under Fire: Perspectives on the Work of Experienced, Inner City High School Teachers in the United States. Teaching and Teacher Education, 22, 812-825.

Chang, E. C. (2002). Optimism - pessimism and stress appraisal: testing a cognitive interactive model of psychological adjustment in adults. Cognitive Therapy and research, 26(5), 675-90.

Chang, M. L. (2009). An Appraisal Perspective of Teacher Burnout: Examining the Emotional Work of Teachers. Educational Psychology Review, 21, 193-218.

Chen, Q. S., Wen, Z. L., Kong, Y. R., Niu, Q., Hau, K. T. (2017). Influence of Leaders' Psychological Capital on Their Followers: Multilevel Mediation Effect of Organizational Identification. Frontiers in Psychology, 8, 1776-1796.

Cheung G. W., \& Lau R. S. (2008). Testing mediation and suppression effects of latent variables: bootstrapping with structural equation models. Organizational Research Methods, 11, 296-325.

Cheung, H. Y. (2008). Teacher Efficacy: A comparative study of Hong Kong and Shanghai primary in-service teachers. The Australian Educational Researcher, 35(1), 103-123.

Cohen, L., Manion, L., \& Morrison, K. (2011). Research Methods in Education (7 ed.). New York: Routledge.

Collie, R. J., Shapka, J. D., \& Perry, N. E. (2012). School climate and social-emotional learning: Predicting teacher stress, job satisfaction, and teaching efficacy. Journal of Educational Psychology, 104, 1189-1204.

Creswell, J. W. (2012). Educational research: Planning, conducting, and evaluating quantitative and qualitative research (4th ed.). Boston, MA: Pearson.

Cresswell, J. W. (2014). Educational Research: Planning, Conducting, and Evaluating Quantitative and Qualitative Research (4th. ed.). Harlow, Essex: Pearson Education Limited.

Curry, L. A. Snyder, C. R., Cook, D. L., Ruby, B. C., \& Rehm, M. (1997). The role of hope in student-athlete academic and sport achievement. Journal of Personality and Social Psychology, 73, 1257-1267.

Duckworth, A. L., Quinn, P. D., \& Seligman, M. E. P. (2009). Positive Predictors of Teacher Effectiveness. Journal of Positive Psychology, 19, 540-547. 
Emmer, E. T. (1994). Teacher emotions and classroom management. Annual Meeting of the American Educational Research Association. New Orleans.

Folkman, S., Lazarus, R.S., Gruen, R.J., \& Delongis, A. (1986). Appraisal, copying, health status, and psychological symptoms. Journal of Personality and Social Psychology, 50, 571-579.

Fredrickson, B. L. (2001). The role of positive emotions in positive psychology: The broadenand- build theory of positive emotions. American Psychologist, 56, 218-226.

Friedman, I. A. (2004). Directions in teacher training for low-burnout teaching. In E. Frydenberg (Ed.), Thriving, surviving, or going under: Coping with everyday lives ( $\mathrm{pp}$. 305-326). Greenwich, CT: Information Age Publishing. Fassinger, R. E. (1987). Use of structural equation modeling in counseling psychology research. Journal of Counseling Psychology, 34(4), 425-436.

$\mathrm{Fu}, \mathrm{C}$. S. (2014). An Exploration of the Relationship between Psychological Capital and the Emotional Labor of Taiwanese Preschool Teachers. Journal of Studies in Social Sciences, 7, 226-246.

Gallegher, W. M., Marques, S. C. \& Lopez, S. J. (2017). Hope and academic Trajectory of College students. Journal of Happiness Studies, 18, 341-352.

Gordon, K., \& Coscarelli, W. (1996). Recognizing and fostering resilience. Performance \& Instruction, 35(9), 14-17.

Gu, Q., \& Day, C. (2007). Teacher's Resilience: A Necessary Condition for Effectiveness. Teaching and Teacher Educations, 23, 1302-1316.

Hair, J. F., Black, W. C., Babin, B. J., \& Anderson, R. E. (2010). Multivariate data analysis (7th ed.). Upper Saddle River, NJ: Prentice Hall.

Hargreaves, A. (1998). The emotional practice of teaching. Teaching and Teacher Education, 14(8), 835-854.

Ho, I. T., \& Hau, K. T. (2004). Australian and Chinese teacher efficacy: similarities and differences in personal instruction, discipline, guidance efficacy and beliefs in external determinants. Teaching and Teacher Education, 20, 313-323.

Isaacowitz, D. M., \& Seligman, M. E. P. (2002). Cognitive style predictors of affect change in older adults. International Journal of Aging and Human Development, 54, 233-253.

Iwanaga, M., Yokoyama, H. \& Seiwa, H. (2004), Coping availability and stress reduction for optimistic and pessimistic individuals, Personality and Individual Differences, 36 (1), 11-22.

Jacobsson, C., Akerlund, M., Graci, E., Cedstrand, E., \& Archer, T. (2016).Teacher team effectiveness and teacher well-being. Clinical and Experimental Psychology, 2(2), 130135.

Kitching, K., Morgan, M., \& O'Leary, M. (2009). It's the Little Things: Exploring the Importance of Commonplace Events for ECTs' Motivation. Teachers and Teaching: Theory and Practice, 15, 43-58.

Kurt, N., \& Demirbolat, A. O. (2019). Investigation of the relationship between psychological capital perception, psychological well-being and Job satisfaction of teachers. Journal of Education and learning, 8(1), 87-99.

Kwon, P. (2002). Hope, defense mechanisms, and adjustment: Implications for false hoe and defensive hopelessness. Journal of Personality, 70, 207-230.

Lee, M. (1997). Relocating location-cultural geography, the specificity of place and the city habitus, In J.M. Guigan (ed.), Cultural Methodologies. London, New Delhi and Thousand Oasks, CA: Sage.

Lee, H. M., Chou, M. J., Chin, C. H., \& Wu, H. T. (2017). The Relationship between Psychological Capital and Professional Commitment of Preschool Teachers: The Moderating Role of Working Years. Universal Journal of Educational Research, 5(5), 891-900. 
Lee, Y. Y. (2018). The effect of psychological capital on the relationship between job satisfaction and job performance in Chinese university teachers. Journal of Northwest Normal University, 12 (6), 125-129.

Luo C. Y. (2019). Analysis of Ideological and political education teachers' psychological capital in Guangdong Private Universities. Century Bridge, 12(2), 58-59.

Luthans, F., \& Youssef, C. M. (2004). Human, social, and now positive psychological capital management. Organizational Dynamics, 33, 143-160.

Luthans, F., Avey, J. B., \& Patera, J. L. (2008). Experimental analysis of a web-based training intervention to develop positive psychological capital. Academy of Management Learning and Education, 7, 209-221.

Luthans, F., Avolio, B. J., Avey, J. B. \& Norman, S. M. (2007). Positive psychological capital: measurement and relationship with performance and satisfaction, Personnel Psychology, 60(3), 541-572.

Luthans, F., Avolio, B. J., Avey, J. B. \& Norman, S. M. (2007). Positive psychological capital: measurement and relationship with performance and satisfaction, Personnel Psychology, 60(3), 541-572.

MacIntyre, P., Gregersen, T., \& Mercer, S. (Eds.) (2016) Positive Psychology in SLA. Bristol: Multilingual Matters.

Mercer, S. (2016). Review: International perspectives on motivation: Language learning and professional challenges. ELT Journal, 70(2), 227-230.

Mojavezi, A., \& Tamiz, M. P. (2012). The impact of teacher self-efficacy on the students' motivation and achievement. Theory and Practice in Language Studies, 2(3), 483-491.

Reichard, R. J., Avey, J. B., Lopez, S., \& Dollwet, M. (2013). Having the will and finding the way: A review and meta-analysis of hope at work. The Journal of Positive Psychology, 8(4), 292-304.

Rizvi, M., \& Elliot, B. (2005). Teachers' perceptions of their professionalism in government primary schools in Karachi, Pakistan. Asia-Pacific Journal of Teacher Education, 33(1), 35-52.

Ross, R., Altmaier, E., \& Russell, D. (1989). Job stress, social support, and burnout among counseling center staff. Journal of Counselling Psychology, 36(4), 464-470.

Salgado, J. F. (2005). Personality and social desirability in organizational settings: Practical implications for work and organizational psychology. Papeles del Psicólogo, 26, 115128.

Scheier, M. F., \& Carver, C. S. (1985). Optimism, coping, and health: Assessment and implications of generalized outcome expectancies. Health Psychology, 4(3), 219-247.

Seligman et al. (2011)

Seligman, M. E. P. (1998). Building human strength: Psychology's forgotten mission. APA Monitor, 29(1), 2-21.

Seligman, M. E. P. (2002). Authentic happiness. New York: Free Press.

Shen, X., Yang, Y. L., Wang, Y., Liu, L., Wang, S., and Wang, L. (2014). The association between occupational stress and depressive symptoms and the mediating role of psychological capital among Chinese university teachers: a cross-sectional study. BMC Psychiatry, 14, 329.

Snyder, C.R., Irving, L., \& Anderson, J. R. (1991). Hope and health: Measuring the will and the ways. In C.R. Snyder \& D.R. Forsyth (Eds.), Handbook of social and clinical psychology: The health perspective (pp.285-305). Elmsford, New York: Pergamum Press.

Snyder, C. R. (2002). Hope theory: Rainbows in the mind. Psychological Inquiry, 13(4), 249275.

Stajkovic, A. D., \& Luthans, F. (1998). Self-efficacy and work-related performance: A metaanalysis. Psychological Bulletin, 124(2), 240-261. 
Sutton, R. E., \& Wheatley, K. F. (2003). Teachers' emotions and teaching: A review of the literature and directions for future research. Educational Psychology Review, 15, 327358.

Wentzel, K. R., Battle, A., Russell, S. L., \& Looney, L. B. (2010). Social supports from teachers and peers as predictors of academic and social motivation. Contemporary Educational Psychology, 35, 193-202.

Yeliz, T. D. (2016). Development of classroom management scale for science teachers. Universal Journal of Educational Research, 4(9), 1950-1957. 